13. Peterson, R. E., and Wyngaarden, J. B., Guerra, S. L., Brodie, B. B., and Bunim, J.: The physiologic disposition and metabolic fate of hydrocortisone in man. J. Clin. Invest., 34: 1779 (1955).

14. Peterson, R. E.: Determination of urinary neutral 17-ketosteroids. In: D. Seligson: Standard Methods of Clinical Chemistry, Vol. 4 (Academic Press. New York, 1963)

15. Rappaport, R., Forest, M. G., Bayard, F., Duval-Beaupere, G., Blizzard, R. M. and Migeon, C. J.: Plasma androgens and LH in scoliotic patients with premature pubarche. J. Clin. Endocrinol. Metab., 38: 401 (1974).

16. Rosenfeld, R. L: Plasma 17-ketosteroids and 17-beta hydroxysteroids in girls with premature development of sexual hair. J. Pediat., 79: 260 (1971).

17. Rudd, B. T., Rayner, P. H. W., Smith, M. R., Holder, G., Jwani, S. K. M., and Theodourdis, C. G.: Effect of human chorionic gonadotrophin on plasma and urine testosterone in boys with delayed puberty. Arch. Dis. Childhood, 48: 590 (1973).

18. Silverman, S. H., Migeon, C., Rosemberg, E., and Wilkins, L.: Precocious growth of sexual hair without other secondary sexual development: "premature pubarche," a constitutional variation of adolescence. Pediatrics, $l: 426$ (1952)

19. Stuart, H. C., and Meridith, H. V.: Use of body measurements in the school health program. Amer. J. Pub. Health, 36: 1365 (1946).

20. Talbot, N. B Sobel, E. H. McArthur, J. W., and Crawford, J. D.: Functional Endocrinology from Birth to Adolescence (Harvard University Press, Cambridge, Mass., 1952).

21. Vestergaard, P., Raabo, E., and Vedos, S.: Determination of urinary testosterone in men, women, and children. Clin. Chim. Acta, 14: 540 (1966).
22. Visser, H. K. A., and Degenhart, H. J.: Excretion of six individual 17-ketosteroids and testosterone in four girls with precocious sexual hair (premature adrenarche). Helv, Paediat. Acta, 21: 409 (1966).

23. Zurbrïgg, R. P., and Gardner, L. I.: Urinary $C_{19}$ steroids in two girls with precocious sexual hair. J. Clin. Endocrinol. Metab., 23: 704 (1963).

24. New England Nuclear, Boston, Mass.

25. Schwartz-Mann, Orangeburg, N. J.

26. Burdick and Jackson Laboratories.

27. K \& K Laboratories, Plainview, N.Y.

28. Bachmeier and $\mathrm{Co}$

29. Eastman Kodak, Rochester, N. Y.

30. Packard Instrument Co.. Downers Grove, III.

31. Warner-Lambert.

32. Armour Pharmaceutical Co., Chicago, III

33. Dr. Maria I. New is a recipient of a Career Scientist Award of the Health Research Council of The City of New York under contract I-48I and U-2204.

34. This investigation was supported by the United States Public Health Service, National Institutes of Health Training Grant Award AM 5350; United States Public Health Service, National Institutes of Health Award HD 72; and United States Public Health Service Division of Research Facilities and Resources, Clinical Research Center Grant Award RR 47.

35. Requests for reprints should be addressed to: Y. Doberne, M.D. Division of Pediatric Endocrinology. The New York Hospital-Cornell Medical Center, New York, N. Y. 10021 (USA).

36. Accepted for pub'ication June 25, 1975 .

\title{
An Analysis of a Rebreathing Method for Measuring Lung Volume in the Premature Infant
}

\author{
ROBERTO RONCHETTI, JANET STOCKS, IAN KEITH, AND SIMON GODFREY(17) \\ Department of Paediatrics and Neonatal Medicine, Hammersmith Hospital, London. England
}

\section{Extract}

Functional residual capacity (FRC) and thoracic gas volume (TGV) were measured in 20 infants, of whom 11 were healthy preterm infants, 5 were recovering from the respiratory distress syndrome ( $R D S$ ), and $\mathbf{4}$ had other pulmonary problems. In addition, some of the theoretical aspects of rebreathing techniques, including the lung to bag $\mathrm{N}_{2}$ difference at equilibrium, were studied by constructing a simple digital computer model of the system.

In both the normal preterm infants and the post-RDS group, the TGV was significantly greater than the FRC $(0.02>P>0.01)$, indicating the presence of trapped gas (Fig. 2). The mean time taken to reach equilibrium during rebreathing was $44 \mathrm{sec}$ in the normal infants and $52 \mathrm{sec}$ in the post-RDS group (Table 2). In one infant with generalized cystic lung disease, equilibrium was not achieved even after $3 \mathrm{~min}$ of rebreathing (Fig. 1 ).

The computer-generated analysis of rebreathing for a normal 3-kg infant is shown in Figure 3, with an in vivo curve for comparison. The rapid equilibration of $N_{2}$ was completed within 55 sec but, as in the in vivo experiments, there was a change in slope of the line after $1.7 \mathrm{~min}$. It can be seen from Table 3 that, if a small initial bag volume $(100 \mathrm{ml})$ is used, $30 \mathrm{sec}$ of rebreathing is adequate for equilibration only when FRC and dead space are normal, and errors would occur if either were enlarged.

The computer study showed that the gradient for $\mathbf{N}_{2}$ between bag and lung at equilibrium is of the order of $0.2-0.37 \%$ which would cause a negligible error when calculating FRC and assuming that lung $\mathrm{N}_{2}$ is equal to the measured bag $\mathbf{N}_{2}$.

The combined in vivo and computer studies served to validate the rebreathing technique as a method for measuring FRC, and have enabled it to be modified for use even in small or very sick infants with poor ventilation. The most useful procedure to employ would seem to be to use an initial bag volume of $150-200 \mathrm{ml}$ and to continue the rebreathing for $1.5-2 \mathrm{~min}$, with samples being taken for analysis at approximately 20 -sec intervals.

\section{Speculation}

Computer simulation of rebreathing by infants could be used to explore gas mixing under various conditions. The pattern of mixing might reflect maturation of lung function in the preterm or sick neonate.

Lung volume in infancy can be measured readily by standard procedures which are used for older children and adults, providing that the equipment is suitably scaled down, as has been shown for the inert gas dilution technique (12), for nitrogen washout (14), and for whole-body plethysmography (1). However, these techniques require considerable instrumentation and are rarely suitable for studying very small or seriously ill infants or for general use where the necessary apparatus and expertise are not available, and 
consequently other methods have been developed. A most successful procedure has been used by Krauss and Auld (8) in which the infant simply rebreathes from a bag containing $12-14 \%$ helium in oxygen for about $30 \mathrm{sec}$. Using this technique they have shown clearly the extent of gas trapping which is seen in normal premature infants $(9)$.

When attempting to use this method in sick infants, one is faced with the problem of having to continue rebreathing long enough to ensure equilibration, while all the time the lung-bag $\mathrm{CO}_{2}$ concentration is continuing to rise, and bag volume is shrinking. Equilibration between lungs and bag during rebreathing is a romplex process which involves not only gas mixing, but changes in the respiratory exchange ratio $\left(\mathrm{CO}_{2}\right.$ evolved $/ \mathrm{O}_{2}$ consumed $)$, as $\mathrm{CO}_{2}$ excretion diminishes in the face of the rising bag $\mathrm{CO}_{2}$ concentration in the same way as during breath-holding (10). Ideally, it is therefore necessary to make serial measurements of bag $\mathrm{N}_{2}$ concentration and bag volume in order to calculate FRC and to ensure that equilibration is complete. A single estimate after $30-60 \mathrm{sec}$ as used by Krauss and Auld (8) is probably adequate for most normal infants if a small bag is used, but it is impossible to be sure of equilibration in the sick infant without prolonging the rebreathing (as they did in a few of their patients). However, once the rebreathing period is prolonged beyond about $30 \mathrm{sec}$, increasing complications arise in the equilibration process (7), which must be taken into consideration when analyzing the results.

In order to study this subject more fully, we decided to carry out an analysis of a simple rebreathing procedure in premature infants, using serial sampling, and compared the results with measurements of TGV made plethysmographically. In addition, we explored some of the theoretical aspects of rebreathing techniques, including the lung to bag $\mathrm{N}_{2}$ difference at equilibrium (7), by constructing a simple digital computer model of the system. We were then able to define the optimal conditions for rebreathing measurements of FRC, and for obtaining additional information on mixing efficiency, by noting the time needed for equilibration.

\section{SUBJECTS AND METHODS}

Measurements were made on 20 infants from the neonatal special care unit as part of the routine measurement of lung function for clinical evaluation and assessment of progress. Some details of these infants are given in Table 1 . The group consisted of 11 healthy preterm infants, 5 recovering from respiratory distress syndrome, and 4 with other pulmonary problems. Both FRC and TGV were measured in 16 infants and FRC alone in the remaining 4 infants. Sedation was not necessary in order to measure functional residual capacity, but since concurrent measurements of thoracic gas volume were also being made, all infants were sedated lightly with $40 \mathrm{mg} / \mathrm{kg}$ chloral hydrate, and were studied $30-60 \mathrm{~min}$ after a feed.

\section{FUNCTIONAL RESIDUAL CAPACITY}

Functional residual capacity and mixing efficiency were measured by a rebreathing technique. A small anesthetic bag $(500 \mathrm{ml})$ was filled with $400 \mathrm{ml}$ of humidified $\mathrm{O}_{2}$ at room temperature and a sample, of measured volume $(20-30 \mathrm{ml})$, was taken for analysis. The remaining $370-380 \mathrm{ml}$ was connected to the infant at the end of a normal expiration by means of a three-way stopcock and a small anesthetic mask, which was sealed to the face with the aid of silicone putty. For the purposes of the present study, rebreathing was prolonged for 2-3 min, and samples were removed from the bag at known intervals of approximately $2030 \mathrm{sec}$, the sample syringes being continuously flushed to ensure good mixing. After the last sample, the stopcock was closed and the final bag volume was measured. The whole procedure was repeated two or three

Table 1. Clinical details of infants

\begin{tabular}{|c|c|c|c|c|c|c|}
\hline & \multirow[b]{2}{*}{ No. } & \multirow[b]{2}{*}{$\begin{array}{l}\text { Gestational } \\
\text { age at birth, } \\
\text { weeks }\end{array}$} & \multirow[b]{2}{*}{$\begin{array}{l}\text { Birth } \\
\text { wt, kg }\end{array}$} & \multicolumn{3}{|c|}{ At time of study } \\
\hline & & & & $\begin{array}{l}\text { Age, } \\
\text { days }\end{array}$ & $\begin{array}{l}\text { Weight, } \\
\text { kg }\end{array}$ & $\begin{array}{l}\text { Length, } \\
\mathrm{cm}\end{array}$ \\
\hline \multirow[t]{11}{*}{ A. Healthy, normal, premature infants } & $I$ & 33.0 & 1.84 & 28 & 2.24 & 45 \\
\hline & 2 & 35.0 & 1.74 & 23 & 1.90 & 44 \\
\hline & 3 & 33.0 & 1.84 & 21 & 2.20 & 44 \\
\hline & 4 & 36.0 & 2.60 & 8 & 2.60 & 7 \\
\hline & 5 & 30.0 & 1.58 & 40 & 2.50 & 48 \\
\hline & 6 & 35.0 & 2.00 & 5 & 1.92 & 46 \\
\hline & 7 & 34.0 & 2.20 & 4 & 2.00 & 47 \\
\hline & 8 & 37.0 & 2.24 & 13 & 2.10 & 46 \\
\hline & 9 & 36.0 & 2.00 & 12 & 2.04 & 47 \\
\hline & 10 & 33.0 & 1.38 & 26 & 1.90 & 45 \\
\hline & 11 & 36.5 & 2.20 & 11 & 2.49 & 47 \\
\hline Mean & & 34.4 & 1.96 & 17 & 2.17 & 46 \\
\hline SEM & & 0.6 & 0.11 & 3 & 0.08 & 0.4 \\
\hline \multirow[t]{5}{*}{ B. Post-RDS } & 12 & 35.0 & 2.55 & 8 & 2.16 & 48 \\
\hline & 13 & 30.0 & 1.43 & 32 & 1.90 & 46 \\
\hline & 14 & 37.0 & 2.70 & 11 & 2.60 & 49 \\
\hline & 15 & 36.0 & 2.60 & 6 & 2.60 & 48 \\
\hline & 16 & 35.0 & 1.70 & 19 & 1.90 & 46 \\
\hline Mean & & 34.6 & 2.19 & 15 & 2.23 & 47 \\
\hline SEM & & 0.3 & 0.26 & 5 & 0.16 & 0.6 \\
\hline \multicolumn{7}{|l|}{ C. Others } \\
\hline Agenesis, lung & 17 & 35.0 & 1.79 & 27 & 2.20 & \\
\hline $\begin{array}{l}\text { Generalized hyperinflation and } \\
\text { Fallot's tetralogy }\end{array}$ & 18 & 38.0 & 2.80 & 13 & 3.00 & \\
\hline Cystic fibrosis & 19 & 39.0 & 2.85 & 49 & 3.55 & \\
\hline Transient tachypnoea & 20 & 40.0 & 3.88 & 4 & 3.95 & \\
\hline
\end{tabular}


times at intervals of $10 \mathrm{~min}$ and the mean result calculated. The samples were analyzed for gas composition using a respiratory mass spectrometer for convenience, but could equally well have been analyzed with an $\mathrm{N}_{2}$ meter or by difference if $\mathrm{O}_{2}$ and $\mathrm{CO}_{2}$ were measured with more simple apparatus. The FRC was calculated by the following equation which allows for the $\mathrm{N}_{2}$ removed in the samples, and for the total instrumental dead space $(6 \mathrm{ml})$, with the final value being corrected to body temperature, pressure, and saturation.

$$
\begin{aligned}
\mathrm{FRC}=\mathrm{F}_{\mathrm{f}} \mathrm{N}_{2}\left(\mathrm{VB}_{\mathrm{f}}+\mathrm{VD}\right) \times \mathrm{VS}\left(\mathrm{F}_{2} \mathrm{~N}_{2}+\mathrm{F}_{3} \mathrm{~N}_{2}+\text { etc. }\right) & \\
& -\mathrm{VB}_{\mathrm{i}} \times \mathrm{F}_{1} \mathrm{~N}_{2}-\mathrm{VD} \times 79.6 \mathrm{ml}
\end{aligned}
$$

$79.6-\mathrm{F}_{\mathrm{f}} \mathrm{N}_{2}$

where $F_{f} N_{2}=$ final bag $N_{2}$ concentration, $V B_{f}=$ final bag volume, $\mathrm{VD}=$ apparatus dead space, $\mathrm{VS}=$ sample volume, $\mathrm{F}_{2} \mathrm{~N}_{2}+$ etc. $=$ $N_{2}$ concentration of samples, $V B_{1}=$ initial bag volume, and $F_{1} N_{2}$ $=$ initial bag $\mathrm{N}_{2}$ concentration. All calculations were based on the volume of the bag after removal of the initial sample, i.e., on 380 $\mathrm{ml}$.

In addition, the $\mathrm{N}_{2}$ concentration of the sample was plotted against rebreathing time in order to determine the time taken to reach equilibrium $\left(\mathrm{T}_{\mathrm{eq}}\right)$ as shown by a uniformly rising concentration (see below).

Oxygen consumption $\left(\dot{\mathrm{V}}_{2}\right)$ was also calculated from the shrinkage in bag volume after allowing for sampling and replacement by $\mathrm{CO}_{2}$ as follows:

$$
\begin{aligned}
\mathrm{VO}_{2}=\mathrm{VB}_{\mathrm{i}}-\left(\mathrm{VB}_{\mathrm{f}}+\mathrm{VS} \times \mathrm{n}\right)+\underset{\mathrm{f}}{\mathrm{F}_{\mathrm{CO}}\left(\mathrm{VB}_{\mathrm{f}}+\mathrm{FRC}+\mathrm{VD}\right)+} \\
\mathrm{VS}\left(\mathrm{F}_{2} \mathrm{CO}_{2}+\mathrm{F}_{3} \mathrm{CO} \mathrm{O}_{2}+\text { etc. }\right) \mathrm{ml}
\end{aligned}
$$

The symbols are analogous to those above and $n=$ number of samples removed. The calculated $\dot{\mathrm{V}}_{2}$ was corrected to standard temperature and pressure of dry gas

\section{THORACIC GAS VOLUME}

The TGV was measured with a whole-body, constant volume, infant plethysmograph using the standard occlusion technique of Dubois et al. (6). The infant slept in the supine position during the test and results were calculated from the chart record obtained when box pressure and mask pressure were completely in phase. The procedure was repeated two or three times and the mean result calculated. The instrumental dead space $(8 \mathrm{ml})$ was subtracted from the calculated result to give the TGV. The plethysmograph was calibrated dynamically for each infant.

\section{COMPUTER SIMULATION FOR REBREATHING}

In order to analyze the dynamics of rebreathing, a simple digita computer program was written in Fortran (SIMSIM), copies of which can be obtained from the authors on request. The program carried out a breath-by-breath analysis of inspiration and expiration to give the composition of lung and bag $\mathrm{O}_{2}, \mathrm{CO}_{2}$, and $\mathrm{N}_{2}$ as well as the volume of the system at any point in time. The input variables were FRC, bag volume, lung volume, tidal volume, physiologic plus instrumental dead space, frequency, $\dot{\mathrm{VO}}_{2}$, gas exchange ratio $(\mathrm{R})$, and initial lung and bag gas concentrations. The loop could be interrupted at will to change any input variable so that it was possible to simulate the increase in ventilation and decrease in $\mathrm{R}$ which occurred during rebreathing. For the present study we used input variables appropriate for a $3-\mathrm{kg}$ term infant based on data collected in this laboratory. Tidal volume was increased from an initial value of $23-40 \mathrm{ml}$ at the end of rebreathing, while frequency was held constant at $55 / \mathrm{min}$ in conformity with our present observations of frequency during rebreathing. In similar fashion $\mathrm{R}$ was decreased from 0.75 for the first $30 \mathrm{sec}$ to 0.3 by the end of $3 \mathrm{~min}$ of rebreathing in accordance with our experimental observations. Oxygen consumption was taken as $30 \mathrm{ml} / \mathrm{min}$ based on our observations (see below) and data for nonbasal infants (5); initial bag $\mathrm{N}_{2}, \mathrm{CO}_{2}$, and $\mathrm{O}_{2}$ were taken as $1 \%, 0$, and $99 \%$ and initial lung $\mathrm{N}_{2}, \mathrm{CO}_{2}$, and $\mathrm{O}_{2}$ as $79.6 \%, 5 \%$, and $15.4 \%$, respectively.
In a later version of the program, tidal volume was increased automatically in response to rising lung (and hence arterial) $\mathrm{CO}_{2}$ using mean data for $\mathrm{CO}_{2}$ sensitivity (2). This resulted in a more rapid rise of tidal volume but did not affect the equilibration procedure, which took place before significant differences arose between the original and modified models. Likewise, substitution of input parameters more appropriate to smaller infants had no significant effect on the conclusions about mixing. The results for the average $3-\mathrm{kg}$ infant are presented below.

\section{RESULTS}

The accuracy of the FRC rebreathing method was estimated by using a dummy lung of $100-\mathrm{ml}$ volume and the experimental result was usually within $1 \mathrm{ml}$. Reproducibility was assessed for both FRC and TGV studies by calculating the coefficient of variation (CV) for paired estimates from the formula

$$
\mathrm{CV}=\frac{\text { SD of difference between pairs }}{\text { Mean of all values } \times \sqrt{2}} \times 100
$$

The CV for 25 pairs of observations of FRC was $11 \%$ and for 19 pairs of observations of TGV it was $5 \%$.

The typical patterns of rising bag $\mathrm{N}_{2}$ concentration in a normal preterm infant and in a baby with getıeralized hyperinflation due to cystic lung lesions are shown in Figure 1. There was rapid mixing within $60 \mathrm{sec}$ in all the normal infants (mean $=44 \mathrm{sec}$ ), but in the sick infant mixing was incomplete even after 3 min of rebreathing. It can be seen that after the mixing phase in the normal infant, there is a linear portion, the slope of which alters at about $1.5 \mathrm{~min}$. This alteration in shape was seen in almost every trace from normal infants. The continuing rise in bag $\mathrm{N}_{2}$ after mixing reflects the continuing bag shrinkage due to $\mathrm{O}_{2}$ uptake and reduced $\mathrm{CO}_{2}$ excretion. It is evident that bag $\mathrm{N}_{2}$ never reaches a totally steady level in the rebreathing procedure, and FRC can only be calculated if bag volume is known at the time when $\mathrm{N}_{2}$ concentration is measured, after complete mixing. As will be seen below, this occurs by the first part of the linear slope. The mixing time $\left(\mathrm{T}_{\mathbf{e q}}\right)$ can be determined, as shown in Figure 1, from the back extrapolation of this part of the record. Calculation of FRC can be undertaken by measuring bag $\mathrm{N}_{2}$ and bag volume at any time after $\mathrm{T}_{\text {eq }}$ and gives the same answer.

The comparison between FRC, measured by rebreathing, and TGV, measured by plethysmography, is shown in Figure 2 and detailed in Table 2. The FRC was very similar in the normal preterm infants and the five infants who were recovering after earlier RDS. The four infants with other lung problems cannot be considered as a group because of their differing conditions and ages. In both the normal preterm infants and the post-RDS group,

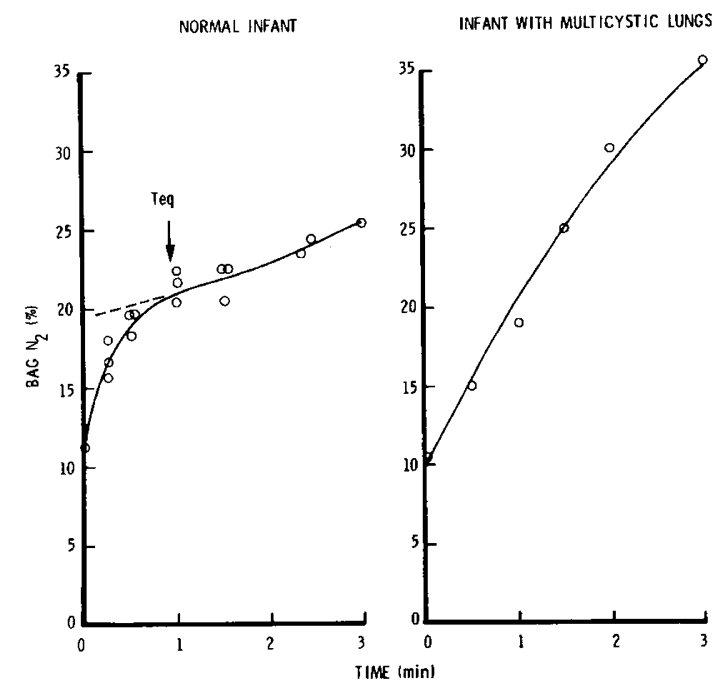

Fig. 1. The equilibration process during rebreathing in normal and multicystic lungs. 
the TGV was significantly greater than the FRC $(0.02<P<$ 0.01 ), indicating the presence of trapped gas. Since equilibration was reached very rapidly in these infants it is obvious that the areas of trapped gas must be either completely unventilated or ventilated so slowly that they do not affect the equilibration process of the well ventilated portion of the lung, which appears to act as a single unit, as has been observed by Krauss et al. (9). The amount of trapped gas was twice as great in the post-RDS infants as in the normal preterm group (Table 2). There was considerable individual variation in the degree to which gas trapping was present in the normal preterm infants, and we found no relationship between the volume of trapped gas and either postconceptual age or age after birth. The volume of trapped gas in the post-RDS group was also unrelated to age, as might be expected, considering the variation in individual severity of the disease. The infants with other lung diseases displayed amounts of trapped gas which varied from normal to very high in the case of the baby with generalized cystic lung disease.

The mean time taken to reach equilibrium during rebreathing $\left(\mathrm{T}_{\text {eq }}\right)$ was $44 \mathrm{sec}$ in the normal group of infants, and $52 \mathrm{sec}$ in the

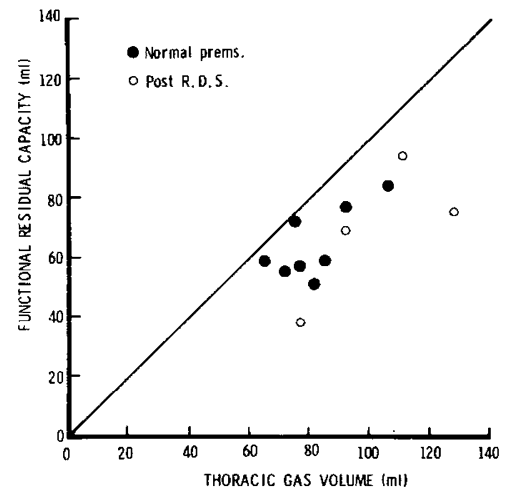

Fig. 2. The presence of trapped gas in infant lungs.
post-RDS group (Table 2). These differences were not significant $(0.1>P>0.05)$. Equilibration in the infant with cystic lung disease was so slow that it was impossible to calculate $T_{\text {eq }}$. The slope obtained from the infant with agenesis $\mathrm{R}$ lung was also unsuitable for back extrapolation.

\section{RESULTS OF COMPUTER SIMULATION OF REBREATHING}

The computer-generated analysis of rebreathing for a normal 3-kg infant, studied exactly as in the real life situation, is shown in Figure 3 with an in vivo curve for comparison. For this analysis, FRC was taken as $100 \mathrm{ml}$, dead space as $12 \mathrm{ml}(6 \mathrm{ml}$ physiologic and $6 \mathrm{ml}$ instrumental), initial bag volume as $380 \mathrm{ml}$, and other variables as listed under Methods. The rapid equilibration of $\mathrm{N}_{2}$ was completed within $55 \mathrm{sec}$ but as in the in vivo experiment, there

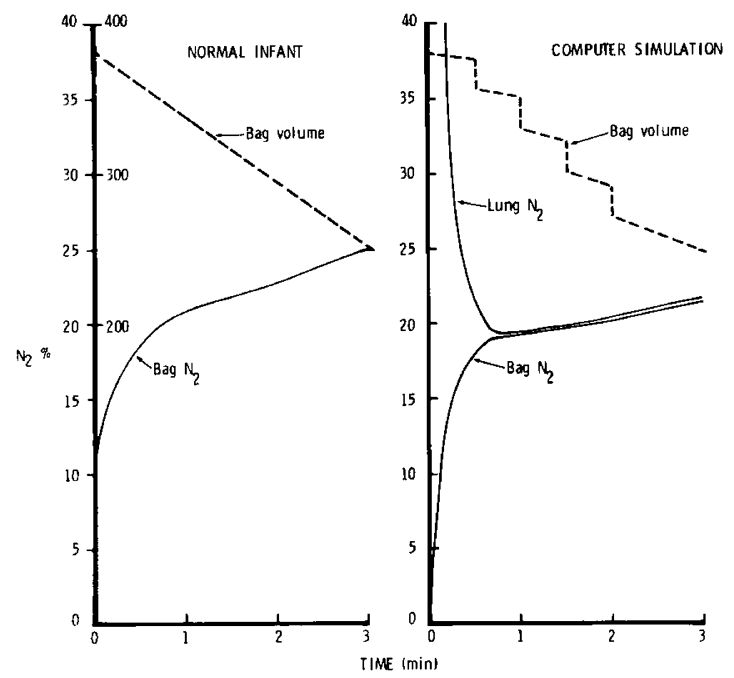

Fig. 3. Comparative analyses of rebreathing by the in vivo curve and computer simulation.

Table 2. Results

\begin{tabular}{|c|c|c|c|c|c|c|c|c|c|c|c|c|c|}
\hline \multirow{2}{*}{\multicolumn{2}{|c|}{ Group }} & \multirow[b]{2}{*}{ No. } & \multicolumn{3}{|c|}{ FRC } & \multicolumn{3}{|c|}{$\mathrm{TGV}$} & \multicolumn{3}{|c|}{ Trapped gas } & \multirow{2}{*}{$\begin{array}{l}\mathrm{T}_{\mathrm{eq}}, \\
\mathrm{sec}\end{array}$} & \multirow{2}{*}{$\begin{array}{c}\mathrm{VO}_{2} \\
\mathrm{ml} / \mathrm{min} / \mathrm{kg}\end{array}$} \\
\hline & & & $\mathrm{ml}$ & $\mathrm{ml} / \mathrm{kg}$ & $\mathrm{ml} / \mathrm{cm}$ & $\mathrm{ml}$ & $\mathrm{ml} / \mathrm{kg}$ & $\mathrm{ml} / \mathrm{cm}$ & $\mathrm{ml}$ & $\mathrm{ml} / \mathrm{kg}$ & $\mathrm{ml} / \mathrm{cm}$ & & \\
\hline \multirow[t]{13}{*}{ A. } & Normal prematures & $l$ & 55 & 24.5 & 1.22 & 72 & 33.0 & 1.60 & 17 & 8.5 & 0.38 & 36 & 13.9 \\
\hline & & 2 & 71 & 37.0 & 1.60 & 75 & 39.0 & 1.70 & 4 & 2.1 & 0.10 & 40 & 7.1 \\
\hline & & 3 & 51 & 23.0 & 1.12 & 82 & 37.0 & 1.86 & 31 & 14.0 & 0.74 & 36 & 10.9 \\
\hline & & 4 & 77 & 29.6 & 1.64 & 92 & 35.3 & 1.95 & 15 & 5.7 & 0.31 & 30 & 8.3 \\
\hline & & 5 & 84 & 33.6 & 1.75 & 106 & 42.4 & 2.20 & 22 & 8.8 & 0.45 & 45 & 9.8 \\
\hline & & 6 & 59 & 30.7 & 1.30 & 65 & 33.8 & 1.40 & 6 & 3.1 & 0.10 & 40 & 7.3 \\
\hline & & 7 & 59 & 29.5 & 1.25 & 85 & 42.5 & 1.80 & 26 & 13.0 & 0.55 & 45 & 6.7 \\
\hline & & 8 & 57 & 27.0 & 1.24 & 77 & 36.6 & 1.70 & 20 & 9.5 & 0.46 & 60 & 8.5 \\
\hline & & 9 & 60 & 29.5 & 1.28 & & & & & & & 60 & 7.0 \\
\hline & & 10 & 62 & 32.7 & 1.38 & & & & & & & 60 & 9.0 \\
\hline & & 11 & 69 & 27.5 & 1.46 & & & & & & & 30 & 9.0 \\
\hline & Mean & & 64 & 29.5 & 1.35 & 81.8 & 37.5 & 1.78 & 17.6 & 8.1 & 0.39 & 44 & 8.9 \\
\hline & SEM & & 3.0 & 1.2 & 0.06 & 4.5 & 1.3 & 0.08 & 3.3 & 1.5 & 0.08 & 2.3 & 0.6 \\
\hline \multirow{5}{*}{\multicolumn{2}{|c|}{ B. RDS }} & 12 & 75 & 34.7 & 1.60 & 127 & 59.0 & 2.60 & 52 & 24.3 & 1.00 & 60 & 10.5 \\
\hline & & 13 & 38 & 20.0 & 0.82 & 77 & 40.5 & 1.67 & 39 & 20.5 & 0.85 & & \\
\hline & & 14 & 94 & 36.0 & 1.90 & 111 & 42.6 & 2.30 & 17 & 6.6 & 0.40 & 50 & 8.2 \\
\hline & & 15 & 69 & 26.5 & 1.40 & 92 & 35.4 & 1.90 & 23 & 8.9 & & & \\
\hline & & 16 & 53 & 27.9 & 1.15 & & & & & & & 30 & \\
\hline & Mean & & 66 & 29.0 & 1.37 & 101.7 & 44.4 & 2.12 & 32.7 & 15.1 & 0.69 & 52 & 11.2 \\
\hline & SEM & & 9.5 & 2.9 & 0.18 & 10.9 & 5.1 & 0.21 & 7.9 & 4.3 & 0.14 & 5.8 & 1.5 \\
\hline \multirow{4}{*}{\multicolumn{2}{|c|}{ C. Others }} & 17 & 37 & 16.8 & & 85 & 38.6 & & 48 & 21.8 & & & 12.4 \\
\hline & & 18 & 137 & 45.6 & & 250 & 83.0 & & 113 & 37.4 & & & 4.4 \\
\hline & & 19 & 93 & 26.2 & & 120 & 33.8 & & 27 & 7.6 & & 45 & 15.5 \\
\hline & & 20 & 114 & 28.9 & & 158 & 40.0 & & 44 & 11.1 & & 30 & 8.3 \\
\hline
\end{tabular}

I FRC: functional residual capacity; TGV: thoracic gas volume. 
REBREATHING METHOD IN PREMATURES

Table 3. Computer-produced simulation of rebreathing experiments

\begin{tabular}{|c|c|c|c|c|c|c|c|c|}
\hline Bag volume & $(\mathrm{ml})$ & $380^{1}$ & 380 & 100 & 380 & 100 & 380 & 100 \\
\hline FRC & $(\mathrm{ml})$ & 100 & 100 & 100 & 100 & 100 & 200 & 200 \\
\hline Dead space & $(\mathrm{ml})$ & 12 & 12 & 12 & 17 & 17 & 17 & 17 \\
\hline Equilibration time & $(\mathrm{sec})$ & 52 & 55 & 32 & 69 & 35 & 97 & 48 \\
\hline Equilibration bag $\mathrm{N}_{2}$ & $(\%)$ & 19.20 & 19.19 & 43.51 & 19.93 & 44.67 & 30.44 & 52.28 \\
\hline $\begin{array}{l}\text { Equilibration bag } \\
\text { volume }\end{array}$ & $(\mathrm{ml})$ & 351.7 & 271.3 & 94.6 & 367.1 & 92.8 & 360.4 & 90.0 \\
\hline $\begin{array}{l}\text { Equilibration } \\
\quad \text { (lung-bag) } \mathrm{N}_{2}\end{array}$ & $(\%)$ & 0.21 & 0.20 & 0.21 & 0.30 & 0.37 & 0.32 & 0.23 \\
\hline $30 \mathrm{sec}$ (lung-bag) $\mathrm{N}_{2}$ & $(\%)$ & 3.09 & 3.09 & 0.25 & 13.94 & 0.64 & 25.20 & 2.11 \\
\hline $60 \mathrm{sec}$ (lung-bag) $\mathrm{N}_{2}$ & $(\%)$ & & & & 0.57 & & 2.40 & \\
\hline $90 \mathrm{sec}$ (lung-bag) $\mathrm{N}_{2}$ & $(\%)$ & & & & & & 0.41 & \\
\hline $\begin{array}{l}\text { Equilibration lung } \\
\mathrm{CO}_{2}\end{array}$ & $(\%)$ & 6.01 & 6.08 & 7.68 & 6.55 & 7.60 & 7.39 & 7.81 \\
\hline
\end{tabular}

${ }^{1}$ Simulated removal of $20-\mathrm{ml}$ samples from bag as in regular experiment. No samples removed in the other simulations. FRC: functional residual capacity.

was a change in slope of the line after $1.7 \mathrm{~min}$. It is important to note the very small final lung-bag $\mathrm{N}_{2}$ difference of $0.2 \%$ after equilibration, and the continuing rise of both in parallel as the bag continues to shrink because of the very low $R$.

In order to study the effect of varying bag size, lung volume, and mixing efficiency, the program was run several times and the results are summarized in Table 3 . It can be seen that removing $20-\mathrm{ml}$ samples from the bag at the standard times had negligible effect on the results. Whatever the conditions, equilibrium was reached more quickly with the $100-\mathrm{ml}$ bag than the $380-\mathrm{ml}$ bag, as would be expected. Equilibration times were prolonged by an increase in FRC or dead space.

The effect of rebreathing for standard times was studied by noting whether the lung bag $\mathrm{N}_{2}$ difference after 30,60 , or $90 \mathrm{sec}$ had yet fallen to that obtained at equilibrium. It can be seen from Table 3 that $60 \mathrm{sec}$ was adequate for the small $(100 \mathrm{ml})$ bag under all conditions tested; the large $(380 \mathrm{ml})$ bag needed $90 \mathrm{sec}$ except for experiments where FRC and dead space were normal $(100 \mathrm{ml}$ and $12 \mathrm{ml}$, respectively). Even for the small bag, $30 \mathrm{sec}$ was only adequate if the FRC and dead space were normal and errors would occur if either were enlarged and the results at $30 \mathrm{sec}$ were used.

The computer study showed that the gradient for $\mathrm{N}_{2}$ between bag and lung at equilibrium is of the order of 0.20 to $0.37 \%$, which would cause a negligible error when calculating FRC and assuming that lung $\mathrm{N}_{2}$ is equal to the measured bag $\mathrm{N}_{2}$. In fact, taking the most extreme example from Table 3 where the difference was $0.37 \%$, the calculated FRC, ignoring the difference, was $98.82 \mathrm{ml}$, whereas, allowing for the difference, it was 100.03 , i.e., an error of $1.2 \%$ which is well within the likely experimental error. It should be noted that this calculation used the actual bag volume at the end of the simulated rebreathe $(92.8 \mathrm{ml})$ and a significant overestimate of FRC of some $4.6 \%$ would have been obtained if the bag volume was assumed to remain at $100 \mathrm{ml}$. Thus, the simulation showed that the lung bag $\mathrm{N}_{2}$ difference causes little error, but ignoring the change in bag volume with even $35 \mathrm{sec}$ of rebreathing results in a significant overestimation of FRC.

\section{DISCUSSION}

The whole question of gas dilution techniques for measuring FRC has interested investigators for many years, on account of the apparently inherent errors in calculating FRC if the final bag and lung concentrations of gas are assumed to be equal (3). Under steady state conditions when $\mathrm{R}$ is less than 1.0, alveolar $\mathrm{N}_{2}$ (or helium, if used) will be more concentrated than inspired $\mathrm{N}_{2}(\mathrm{He})$ because the sum of the partial pressures of alveolar $\mathrm{CO}_{2}$ and oxygen is less than that of inspired $\mathrm{O}_{2}$. This is further complicated by rebreathing from a large closed circuit system, such as in the conventional helium dilution procedure, because the volume of the system diminishes. This may result in spirometer $\mathrm{N}_{2}(\mathrm{He})$ actually being more concentrated than alveolar $\mathrm{N}_{2}(\mathrm{He})$. Herrald and
McMichael (7) attempted to compensate for this by arranging to hold the volume of their system constant, but this resulted in a complicated technique. It is possible that the simple rebreathing method used by Krauss and Auld (8), and modified for use in the present study, could have exaggerated these difficulties, since the $R$ rapidly falls well below 1.0 and the bag volume shrinks, which theoretically could have resulted in a significant difference between the final bag and lung concentrations of $\mathrm{N}_{2}$ (or $\mathrm{He}$ ) even when equilibrium had occurred.

Since it was impracticable to estimate alveolar and bag $\mathrm{N}_{2}$ simultaneously in vivo, we found it necessary to develop the computer model in order to test the validity of this method in the face of these theoretical possibilities. When preparing the program, it was necessary to assume certain values for the diminishing $R$ and the increasing ventilation, and we based these on experimental studies performed within the laboratory. The similarity of the computer-predicted and the in vivo curves suggests that the assumptions that were made were at least reasonable. The rather larger $T_{e q}$ of the computer probably reflects the very precise nature of its determination, compared with the crude judgments by eye for in vivo tests. The chief unknown factors in the computer model were the rate of change of $\mathrm{R}$ and the rate of increase of ventilation. During breath-holding, alveolar $\mathrm{CO}_{2}$ rises much faster than in our computer model since the volume of the system is much smaller in the former case. However, the computer model showed that once mixing had occurred $\mathrm{R}$ had little effect on the final lung-bag $\mathrm{N}_{2}$ difference, and also showed that even if tidal volume increased at a faster rate than that which we had assumed, as suggested by the results of Avery et al. (1), this would have negligible effects on the final results, since the important mixing occurs very early. We found relatively little change in respiratory frequency during our experimental work, although there was individual variation, and we therefore held the rate constant in the model. Cross et al. (4) and Avery et al. (2), in their studies of infants' response to $\mathrm{CO}_{2}$ in the steady state and the effects of rebreathing, respectively, have both observed a rise in frequency as well as tidal volume, but again, the major changes occur too late to have a significant effect on the mixing process.

It was evident from the computer model that only a very small difference between lung and bag $\mathrm{N}_{2}$ remained after equilibration, so that the assumption that they were equal was quite valid. We believe that this final difference simply reflects the balance between rising concentration of $\mathrm{N}_{2}$ in the alveoli (where $\mathrm{O}_{2}$ is being absorbed), and rising concentration of $\mathrm{N}_{2}$ in the bag (because of shrinkage of the system). In addition, alveolar ventilation is continually mixing lung and bag gas so that the net difference is very small indeed. Small departures of alveolar $\mathrm{N}_{2}$ from the initial assumed value due to ventilation-perfusion disturbances would not materially affect results (an error of approximately $\pm 0.5 \mathrm{ml}$ in FRC over the likely range of $\mathrm{N}_{2}$ ).

Of some practical importance is the apparently linear rise in 
both lung and bag $\mathrm{N}_{2}$ after equilibration, which reflects continuing $\mathrm{O}_{2}$ consumption at a steady rate, while $\mathrm{CO}_{2}$ excretion has virtually ceased. The break in the slope of this line was seen both in vivo and in simulated experiments after approximately 1.5 to $1.7 \mathrm{~min}$ in normal infants, and probably reflects the fact that $\mathrm{R}$ falls rapidly during the first and second min of rebreathing (13). Despite this break, it is still possible to determine $T_{\text {eq }}$ by extrapolating the initial part of the linearly rising bag $\mathrm{N}_{2}$ backwards, since the model shows mixing to be complete by this phase. The computer-derived result lends support to the use of this method for the in vivo measurements.

The combined in vivo and computer studies performed in the present investigation have served to validate the rebreathing technique as a method for measuring FRC, and have enabled it to be modified for use even in small or very sick infants with poor ventilation. We have found that, when applying the method to sick infants, the use of a more prolonged rebreathing method, a larger initial bag volume, and serial sampling are useful safeguards to ensure that equilibration is complete, and provide further information on the nature and rapidity of the mixing process. During the latter part of this study, the procedure was modified so that $20-\mathrm{ml}$ samples were withdrawn at 15 -sec intervals during the first minute, and $30 \mathrm{sec}$ thereafter. This technique provided even more accurate information on the equilibration process. The value of taking serial samples to document mixing was especially impressed upon us by the study of the infant with generalized pulmonary hyperinflation.

The results of the present study have largely confirmed the observations of previous workers. In our group of normal preterm infants, the mean $F R C$ was $1.38 \mathrm{ml} / \mathrm{cm}$, which is very similar to the $1.2 \mathrm{ml} / \mathrm{cm}$ reported by Krauss (9) for a group of normal preterm infants of similar weight and age.

The phenomenon of gas trapping in newborn infants has been documented by several authors and our mean figure of $8.1 \mathrm{ml} / \mathrm{kg}$ in normal premature infants corresponds closely to the $9.3 \mathrm{ml} / \mathrm{kg}$ observed by Nelson et al. (11) in their concurrent study of TGV and FRC. We are not in a position to confirm the reduction in TGV with subsequently diminishing gas trapping which has been reported to occur with growth (9). We did in fact detect trapped gas in infants who were relatively old, although it is possible that these infants might have been found to have even greater discrepancies between TGV and FRC had they been studied at an earlier age.

The large volume of trapped gas which we found in the group of infants who had recently recovered from RDS was due to their elevated TGV since their FRC was virtually identical with that of normal preterm infants (Table 2). The normal values for FRC in these infants with a mean age of 15 days is in agreement with the return to normality by this age reported by Tori et al. (15), whereas the elevated TGV is in conformity with our own plethysmographic observations on other infants who had recently recovered from RDS and has also been noted by Auld et al. (1).

In conclusion, we believe that the rebreathing technique of measuring FRC is a simple, practical, and valid method of assessment which can be used even for small or sick neonates with abnormal ventilation. From our theoretical and practical analyses it would seem that the most useful procedure is to employ an initial bag volume of $150-200 \mathrm{ml}$ and to continue the rebreathing for

Copyright @ 1975 International Pediatric Research Foundation, Inc.
1.5-2 $\mathrm{min}$, with samples being taken for analysis at approximately 20 -sec intervals.

\section{SUMMARY}

An analysis of an $\mathrm{O}_{2}$ rebreathing method of measuring functional residual capacity in premature infants has been carried out by in vivo comparisons with measurements of thoracic gas volume in a whole body plethysmograph and by computer simulations. The simple rebreathing method has been shown to give results in agreement with established values and has served to demonstrate gas trapping in healthy premature infants, and even more so in those recovering from respiratory distress syndrome. Serial sampling demonstrated the attainment of equilibration within $1 \mathrm{~min}$ in all but infants with grossly abnormal lungs. Computer simulation closely resembled the in vivo results and served to demonstrate the lack of significant lung to bag $\mathrm{N}_{2}$ differences after equilibration. The practical, theoretical, and clinical aspects of the subject are reviewed.

\section{REFERENCES AND NOTES}

1. Auld P A M Nelson, N M. Cherry, R. B., Rudolph, A. J., and Smith, C. A.: Measurement of thoracic gas volume in the newborn infant. J. Clin. Invest., 42: $476(1963)$.

2. Avery, M. E Chernick, V., Dutton, R. E., and Permutt, S.: Ventilatory response to inspired carbon dioxide in infants and adults. J. Appl. Physiol.. 18: 895 (1963).

3. Christie, R. V.: The lung volume and its subdivisions. J. Clin. Invest.. II: 1099 (1932).

4. Cross, K. W. Hooper, J. M. D., and Oppe. T. E.: The effect of inhalation of carbon dioxide in air on the respiration of the full-term and premature infant. J. Physiol. (London), 122: 264 (1953).

5. Cross, K. W.. Flynn, D. M., and Hill, J.: Oxygen consumption in normal newborn infants during moderate hypoxia in warm and cool environments Pediatrics, 37: 565 (1966).

6. Dubois, A. B., Botelho, S. Y., Bedell, G. N., Marshall, R., and Comroe, J. H. Jr.: A rapid plethysmographic method for measuring thoracic gas volume: a comparison with a nitrogen washout method for measuring functional residual capacity in normal subjects. J. Clin. Invest., 35: 322 (1956).

7. Herrald, F. J. C.. and McMichael, J.: Determination of lung volume: a simple constant volume modification of Christie's method. Proc. Roy. Soc. Ser. B. 126: 49 ! (1939)

8. Krauss, A. N., and Auld, P. A. M.: Measurement of functional residual capacity in distressed neonates by helium rebreathing. J. Pediat.. 77: 228 (1970).

9. Krauss, A. N., and Auld, P. A. M.: Pulmonary gas trapping in premature infants. Pediat. Res., 5: 10 (1971).

10. Mithoefer, J. C.: Mechanism of pulmonary gas exchange and $\mathrm{CO}_{2}$ transport during breath holding. J. Appl. Physiol., 14: 706 (1959)

1. Nelson, N. M., Prod'hom, L. S., Cherry, R. B., Lipsitz, P. J., and Smith, C. A. Pulmonary function in the newborn infant. V. Trapped gas in the normal infant's lung. J. Clin. Invest., 42: 1850 (1963).

12. Ronchetti. R.. Senterre, J., and Geubelle, F.: Functional residual capacity and distribution of the inspired air in the premature baby. Act a Paediat. Belg., 25: 5 (1971).

13. Ronchetti, R. Stocks, J. Keith, I., and Godfrey, S.: Personal observations

14. Strang, L. B., and McGrath, M. W.: Alveolar ventilation in normal newborn infants studied by air wash-in after oxygen breathing. Clin. Sci., 23: 129 (1962).

15. Tori, C. A., Krauss, A. N., and Auld, P. A. M.: Serial studies of lung volume and $\dot{V A} / \dot{Q}$ in hyaline membrane disease. Pediat. Res., 7: 82 (1973).

16. The present address of Dr. R. Ronchetti is: Department of Paediatrics, University of Parma, Italy.

17. Requests for reprints should be addressed to: Simon Godfrey, M.D.. Department of Paediatrics and Neonatal Medicine, Hammersmith Hospital, Du Cane Road, London W12 OHS (England).

18. Accepted for publication June 25,1975 